\title{
Making of a highly useful multipurpose vaccine
}

\author{
GP Talwar*, Priyanka Singh, Nishu Atrey and Jagdish C Gupta \\ GP Talwar*, Priyanka Singh, Nishu Atrey and Jagdish C Gupta
}

\begin{abstract}
Reviewed briefly is the journey taken for development of an immunotherapeutic Vaccine for multibacillary leprosy. The nature of immune deficit in these patients is their inability to react to key antigens of M. leprae. Heterologous approach was adopted to identify a cultivable mycobacteria coded as Mw, now sequenced and named as Mycobacterium indicus pranii (MiP). MiP expediated bacterial clearance and shortened the recovery time of leprosy patients. It converted 65-70\% of lepromin negative BL, LL patients to lepromin positivity status, which is not achieved by treatment with, drugs alone. The vaccine has received approval of The Drugs Controller General of India and USFDA and is being manufactured by M/s Cadilla Pharma.

$\mathrm{MiP}$ is a potent invigorator of both cellular and humoral immune responses and has found many other useful applications. It is effective for treatment of Category II "difficult to treat" tuberculosis patients. In contrast to BCG, it is active in killed autoclaved form. It enhances considerably antibody titres to a potential birth control vaccine against hCG. It cures ugly anogenital warts. It has both preventive and therapeutic action against SP2/O Myelomas.
\end{abstract}

\section{Introduction}

Many scientists especially in developing countries would like to work on a problem relevant to the country, and if possible find a solution to it. Such goal directed research demands initially carrying out basic work to understand the scientific basis of that problem. Thereafter, arises the issue of developing a Product which has the potential of resolving that problem. This work would demand human cell lines or an animal model in which testing can be done. After obtaining positive results, which does not happen always, a new phase of Product development emerges demanding Toxicology, and thereafter with due approval of Ethics committee and Drugs Regulatory Authority, Phase I, Phase II and Phase III Clinical trials would be required to establish the safety and efficacy of the product for human usage. After reaching this stage a competent company has to make the product for eventual marketing and availability to public. This Road is long and takes 10-20 years to reach the end.

Described briefly below is an immunotherapeutic vaccine that we developed for treatment of multibacillary leprosy. It is based on a nonpathogenic cultivable mycobacteria, now named as Mycobacterium indicus pranii (MiP) $[1,2]$. This vaccine has received the approval of The Drugs Controller General of India and also of US FDA. It has been licensed to M/S Cadilla Pharma and is available to the public. Its utility has extended beyond leprosy, in immunotherapy of Category II "difficult to treat" tuberculosis, in cancers such as myelomas, anogenital warts and as adjuvant for the anti-hCG birth control vaccine.

\section{Discovery of MiP}

Studies were carried out to understand the nature of defect in the immune system of those who contract leprosy. 99\% of humans do not develop leprosy. The $1 \%$ who develop the disease manifest a variable pattern ranging from patients who have only 1 minor lesion with hardly any detectable bacilli (tuberculoid leprosy, TT) to those who are loaded with bacilli and have lesions everywhere (lepromatous leprosy, LL). Others fall in between the spectrum TT, BT, BL, LL forms of leprosy.
The nature of defect in LL patients is the inability of their T cells to recognise M. leprae antigens. The October 1978 Golden Jubilee issue of leprosy in India [3] is entirely devoted to our studies carried out to determine the nature of immune deficit in these patients [4]. How could this be overcome? Can a vaccine be developed which could impart the requisite immunity to those lacking it.

Vaccines usually employ the target pathogen in a killed or attenuated form. This approach would not be usable for multibacillary leprosy, as the patient cannot recognise or react to key M. leprae antigens. A heterologous approach was taken. We collected all the known cultivable species of mycobacteria as well as atypical isolates in hospital collections. These were tested for their ability to cause blast transformation of T cells from LL patients. Luckily 5 of these 17 mycobacteria could do so. Thereafter the ability of these mycobacteria to prevent the multiplication of M. leprae in macrophages of LL patients along with their $\mathrm{T}$ cells was investigated. M. leprae, was discovered by Armauer Hansen in Norway, in 1873. He was unable to cultivate this microorganism in any medium. It is an obligatory intracellular parasite, and grows in macrophages. It is a slow grower and requires 13 days to divide. How could one study the ability of the shortlisted 5 mycobacteria to interrupt the multiplication of $M$. leprae in monocyte derived human macrophages was a key problem in our research undertaking at that time. It could not be done by bacterial count, the source of M. leprae was from LL patients and the biopsies contained an unknown number of live and dead M. leprae. We thought of employing ${ }^{3} \mathrm{H}$-thymidine incorporation into DNA as a measure of permissive $M$. leprae multiplication or inhibition of this process $[5,6]$. Macrophages

Correspondence to: G P Talwar, Director Research, Talwar research Foundation, E-8, Neb Valley, Neb Sarai, New Delhi-110068, India, Tel: +91-011-65022405; E-mail: gptalwar@gmail.com

Key words: MiP, leprosy, tuberculosis, anogenital warts, contraception

Received: December 30, 2015; Accepted: January 15, 2016; Published: January 19,2016 
do not divide, nor synthesize DNA, hence would not incorporate ${ }^{3} \mathrm{H}$-thymidine, whereas $M$. leprae if it has to grow would use thymidine for making DNA. Given below in Table 1 is an investigation, which not only showed that radiolabelled thymidine incorporation into DNA was a workable strategy, but also lymphocytes played a key role in enabling or blocking the growth of $\mathrm{M}$. leprae phagocytosed by macrophages. The lymphocytes of Tuberculoid leposy patients were competent to generate the inhibitory signal whereas lymphocytes from multibacillary Lepromatous Leprosy (LL) were incompetent for this task.

The ability of each of the shortlisted 5 mycobacteria to produce macrophage activating factors from lymphocytes of leprosy patients was investigated [7]. A series of investigations were carried out in experimental animals and in patients with their consent and due permission of Ethics Committee to sift out the most eligible strain from amongst the shortlisted 5 mycobacteria. These are reported in cited references.

$\mathrm{Mw}$, a cultivable, non-pathogenic mycobacterium was selected as the most suitable candidate for the vaccine. Figure 1 is an electron micrograph of $\mathrm{Mw}$ now named as MiP.

$\mathrm{MiP}$ retains its properties in killed autoclaved form, which simplified toxicology studies, With approval of the Drugs Controller General of India (DCGI) and Institutional Ethics Committees, clinical trials were conducted with MiP employed as adjunct to the standard Multidrug treatment (MDT) in BL, LL patients [8]. As control, MDT + Placebo (saline) was used for comparison. Inclusion of $\mathrm{Mw}(\mathrm{MiP})$ as adjunct to standard MDT expedited bacterial clearance and shortened

Table 1. Mycobacterial multiplication in cultivated macrophages derived from peripheral blood monocytes of Leprosy patients (from 6).

\begin{tabular}{|c|c|c|c|}
\hline \multirow{2}{*}{$\begin{array}{l}\text { Patient } \\
\text { No. }\end{array}$} & \multirow{2}{*}{$\begin{array}{l}\text { Clinical } \\
\text { Status }\end{array}$} & \multicolumn{2}{|c|}{ CPM ${ }^{3} \mathrm{H}$-thymidine incorporated per $5 \times 10^{5}$ phagocytic cells } \\
\hline & & $\begin{array}{c}\text { Macrophages + Lymphocytes } \\
+ \text { M. leprae }\end{array}$ & Macrophages + M. leprae \\
\hline 1. & LL & 36,458 & 45,628 \\
\hline 2. & LL & 53,929 & 59,596 \\
\hline 3. & LL & 52,354 & 83,476 \\
\hline 4. & TT & 6,332 & 54,969 \\
\hline 5. & TT & 32 & 78,447 \\
\hline 6. & TT & 381 & 26,260 \\
\hline
\end{tabular}

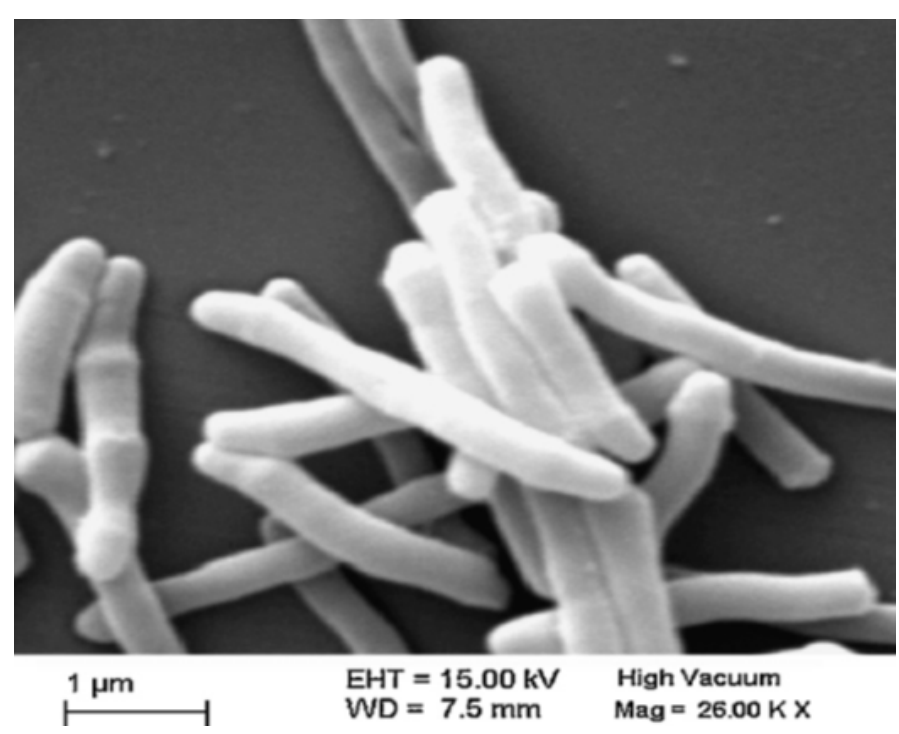

Figure 1. Electron micrograph of autoclaved Mycobacterium indicus pranii (MiP).
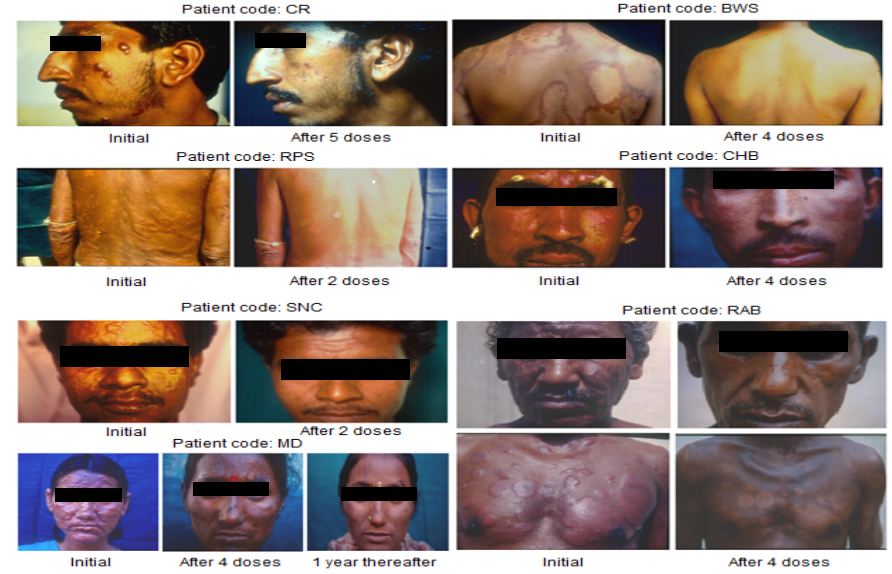

Figure 2. Some representative cases of LL/BL multibacillary patients treated with MDT plus Mw (Mycobacterium indicus pranii) (from 4).

the period of complete recovery. A striking feature of using MiP was that it improved the ugly defacing lesions manifest in leprosy patients, which are seldom improved by treatment with MDT alone. Figure 2 illustrates the remarkable cure and normalcy of leprosy lesions in some of the representative patients.

Another remarkable feature of employing $\mathrm{Mw}$ (MiP) for treatment was the conversion of 65 to $69 \%$ patients from lepromin negativity to lepromin positivity status signifying the ability to resist and prevent the development of the disease on fresh exposure to M. leprae [9]. Patients treated with drugs alone remain lepromin negative and susceptible to leprosy on re-exposure to M. leprae. Also cleared were bacilli from the peripheral nerves.

Phase II, Phase III trials were carried out under experienced Dermatologists in Delhi and Chandigarh [10]. These were then extended to field trials in Kanpur Dehat consisting of 272 villages with population of 420,823 inhabitants. Besides immunotherapy of patients, immunoprophylactic benefits were assessed by vaccinating contacts and family members. Encouraging results were obtained in these field trials $[11,12]$.

$\mathrm{Mw}(\mathrm{MiP})$ vaccine received the approval of the Drugs Controller General of India, as well as of US FDA. To our knowledge this is the first and the only vaccine of its type in the world. It was licensed to $\mathrm{M} / \mathrm{s}$ Cadila Pharma, Ahmedabad for making it available to the Public.

\section{Strategy for Eradication of Leprosy}

MiP will be employed for immunoprophylaxis with the aim of eradicating leprosy. The Indian Council of Medical research (ICMR) along with the National Leprosy Program (NLEP) of the Government of India have decided to undertake a mission oriented field project in four districts of high endemicity of leprosy. Since 2006, the prevalence figures of leprosy in India show a linear plateau, and treatment with standard multidrug regime is not bringing it down. The incidence of new cases of leprosy is remaining high; these are higher than the National prevalence rate. This status is persisting since the past 8 years (Figure 3).

In the new field project to be undertaken under ICMR and NLEP, the index leprosy patient will receive the MIP vaccine over and above the MDT. His family members and contacts would be immunized with MiP twice at an interval of six months with the expectation that their 


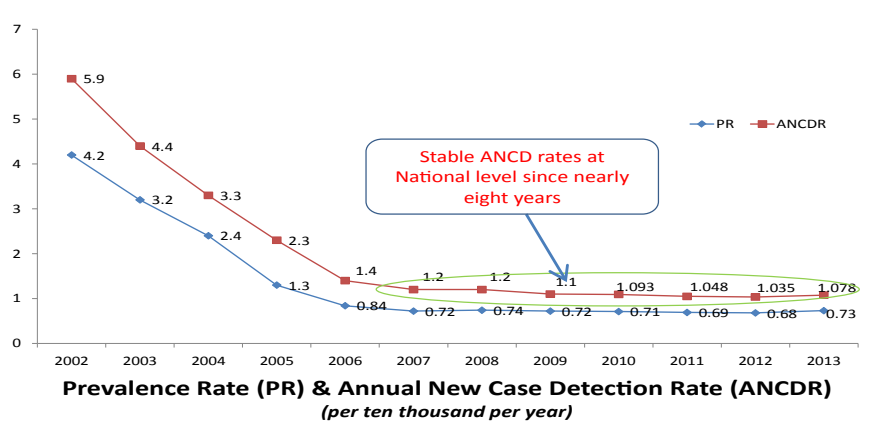

Figure 3. National Leprosy Eradication Programme (NLEP) data on Prevalence and Annual New Case Detection Rates in India. (a)

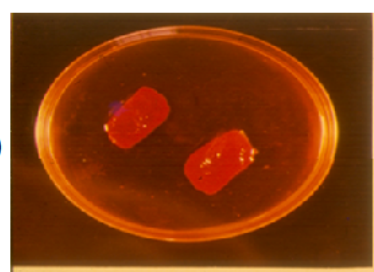

(C)

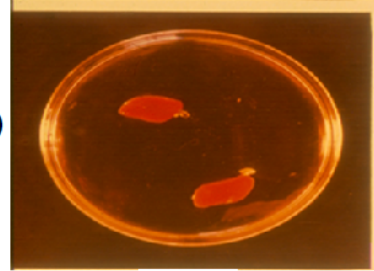

Spleen
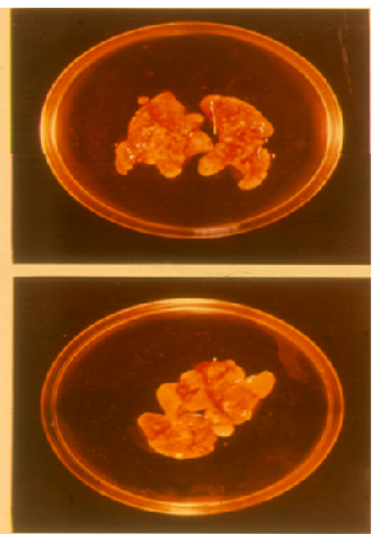

Lungs (b)

(d)
Figure 4. Protection test of $\mathrm{M} w$ against tuberculosis in Guinea pigs. (a) and (b) Guinea pigs challenged with M. tuberculosis $\mathrm{H}_{37} \mathrm{Rv}$. (c) and (d) Immunized with Mw.

immunity is reinforced to evade leprosy on exposure to $M$. leprae from a patient. The utility of immunizing the index case and his contacts with MiP vaccine would be to upgrade their immunity to resist the disease on exposure to $M$. leprae from those suffering from it.

BCG has been employed for vaccination of contacts of leprosy patients in Bangladesh with the idea of enhancing their immunity to resist their becoming leprosy patients. It was observed that $23 \%$ of the contacts did develop leprosy 2-10 months after vaccination with two doses of BCG [13].Thus BCG was not fully protective. In Chandigarh, disseminated cutaneous BCG lesions were observed following immunotherapy with BCG of lepromatous leprosy patients [14]. This unexpected effect of BCG vaccination emerged, as BCG vaccine works only as live bacteria, killed BCG is devoid of the potential of vaccination. In contrast $\mathrm{Mw}$, Mycobacterium indicus pranii retains its efficacy in killed autoclaved state.

\section{Additional applications of MiP}

Besides leprosy and tuberculosis, MiP has proven to be a potent invigorator of both cellular and humoral immune responses. Summarized below are 4 useful applications of MiP.

\section{Tuberculosis}

$\mathrm{Mw}$ (Now $\mathrm{MiP}$ ) shares antigens with both $M$. leprae and $\mathrm{M}$ tuberculosis. The Company to which it was licensed asked us to provide them with a suitable test for evaluation of the bioactivity of each batch of MiP manufactured by them. We proposed that bio efficacy of MiP may be evaluated by its ability to prevent tuberculosis. Guinea pigs immunized with $\mathrm{MiP}(\mathrm{Mw})$ may be challenged with $\mathrm{H}_{37} \mathrm{Rv}$, the virulent strain of M. tuberculosis. Animals immunized with authentic MiP would not have enlarged lungs or spleen, whereas the control animals would manifest these symptoms (Figure 4).

BCG has since long been used in many countries as vaccine for immunization against tuberculosis. In many countries it is effective, whereas in several others including India, it was not found effective to prevent pulmonary tuberculosis in children. There is apparently genetic restriction for action of BCG. It was relevant to enquire whether the same was the case for $\mathrm{MiP}(\mathrm{Mw})$. Experiments were performed in four different genetic strains of mice. BCG protected C57BL and BalbC strains of mice, whereas it did not impart protective immunity to $\mathrm{C} 3 \mathrm{H}$ and CBA strains [15]. MiP, on the other hand protected all strains of mice investigated (Figure 5).

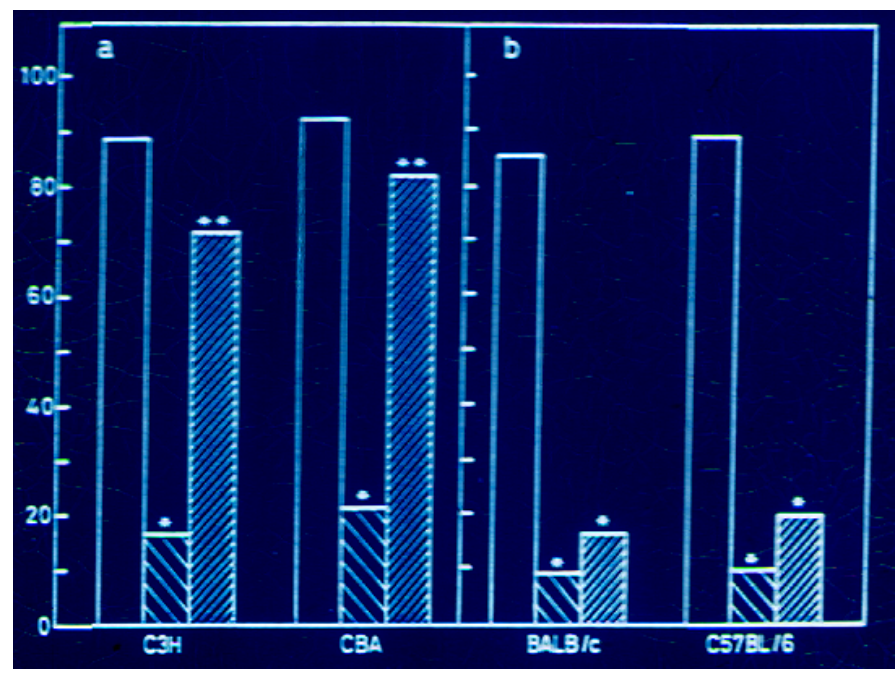

Figure 5. Effect of immunization with killed M.w or live BCG on development of pulmonary lesions in $\mathrm{C} 3 \mathrm{H} / \mathrm{He} \mathrm{NCrl}, \mathrm{CBA} / \mathrm{N}$ (a) and in Balb/c ByJ and $\mathrm{C} 57 \mathrm{BL} / 6 \mathrm{NCrl}$ (b) strains of mice. Animals were immunized either with $10^{7}$ heat-killed Mw s.c. or $10^{4}$ live BCG i.v. Four weeks later, the animals were challenged with $10^{7}$ M. tuberculosis $\mathrm{H}_{37} \mathrm{Rv}$ i.v. four weeks post challenge, the animals were killed and visible lesions in the lungs were recorded. The data plotted are the mean of results obtained from three sets of experiments with $\mathrm{Mw}$ and two sets of experiments with $\mathrm{BCG}$, with $\mathrm{n}=7-10$ animals per group. The data for the non-immunized group of animals are also presented. (from 15).

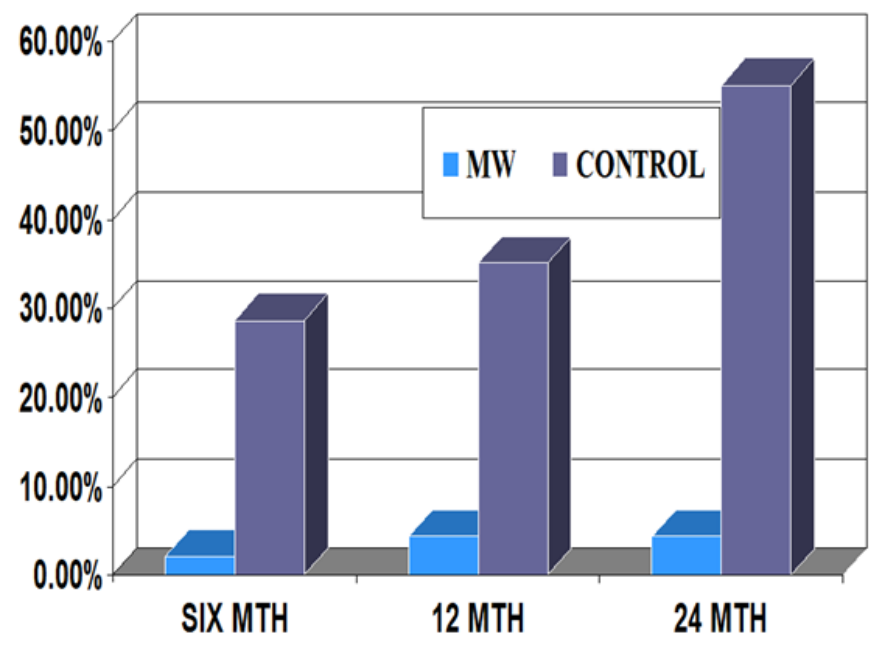

Figure 6. Relapse rate of Category II tuberculosis patients after treatment with MDT alone or MDT+ Mw (MiP). 
Table 2. Outcome of the additive effect of MiP in comparison to MDT alone for therapy of Cat II Tuberculosis patients.

\begin{tabular}{|l|c|c|}
\hline Treatment Description & Cured & Cured (\%) \\
\hline MIP + MDT $(n=49)$ & $48 / 49^{*}$ & 97.96 \\
\hline MDT alone $(n=27)$ & $21 / 27^{* *}$ & 77.77 \\
\hline
\end{tabular}

*Defaulter for 6 doses, sputum negative after intensive phase.

** 2-2+ No effect of therapy

$4-1+$ No effect of therapy
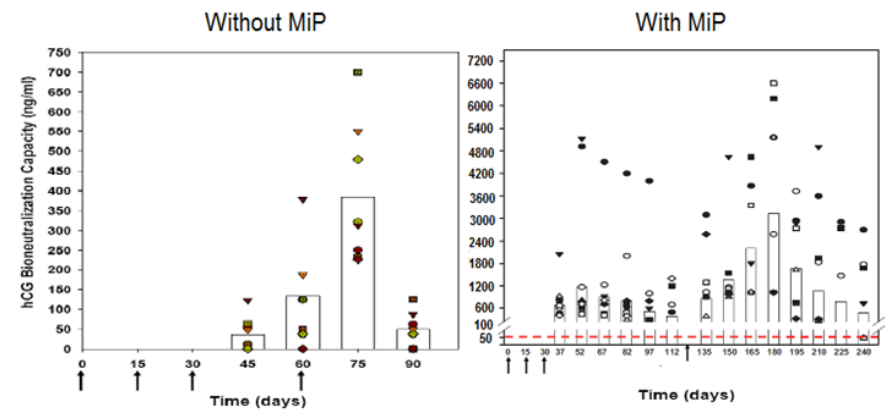

Figure 7. Enhancement of antibody response to hCG $\beta$-LTB vaccine in Balb/c mice by MIP. Mice were immunized intra-muscularly with $2 \mu \mathrm{g}$ of the vaccine adsorbed on alum with or without MIP. Primary immunization consisted of 3 injections given at fortnightly intervals followed by a booster on day 60 or 120 . The symbols represent the titres in a given mouse. Bars give the geometrical Means (from 16). (a)

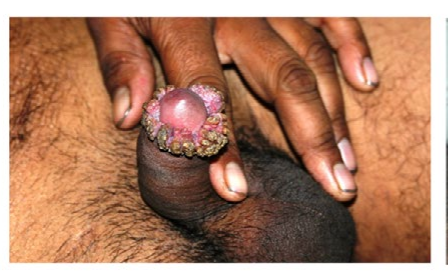

(b)

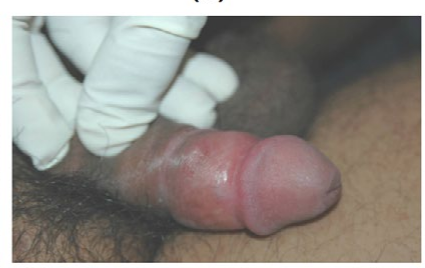

Figure 8. Effect of MiP infections on ugly anogenital warts. (a) A patient with giant condylomata. (b) The lesions completely subsided with intralesional immunotherapy with $\operatorname{MiP}$ (from 17).

Therapeutic trials were conducted in Category II, "Difficult to treat" tuberculosis patients. Inclusion of $\mathrm{Mw}(\mathrm{MiP})$ as adjunct to standard Multidrug Therapy (MDT) cured 48/49 patients, whereas MDT alone was effective in $21 / 27$ patients (Table 2). Furthermore the relapse rate of the disease in patients treated with MDT+ MiP $(\mathrm{Mw})$ was far lower than in those receiving drugs alone (Figure 6).

\section{MiP is a Potent Adjuvant}

$\mathrm{MiP}$ enhances significantly the antibody titres, when used as adjuvant in the recombinant vaccine against hCG [16] (Figure 7).

\section{Anogenital Warts}

MiP cures marvellously ugly ano-genital warts caused by HPV, as observed at the All India Institute of Medical Sciences by Prof. Somesh Gupta [17] ( Figure 8 ).

\section{Myelomas}

MiP prevents and cures SP2/O Myelomas in Balb/c mice as observed by Prof. Dipankar Nandi at the Indian Institute of Sciences Bangalore [18] (Figure 9).

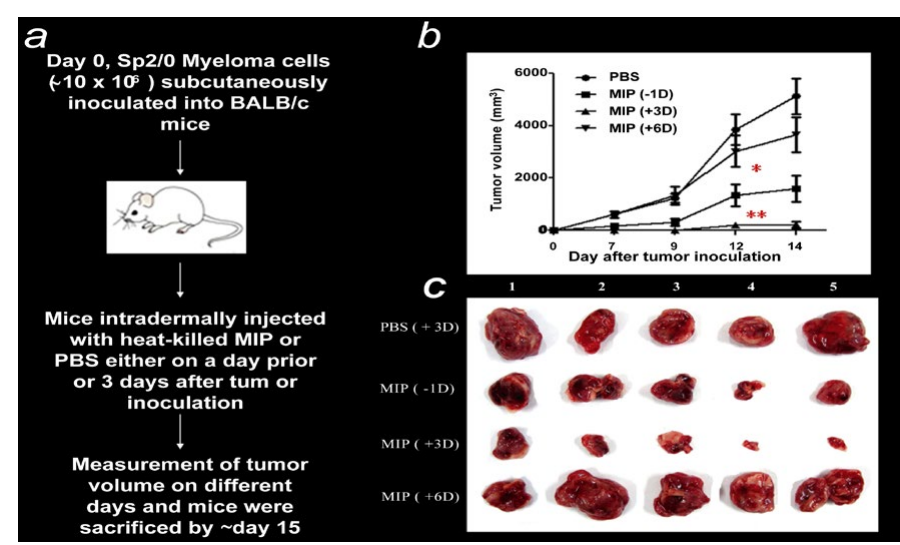

Figure 9. MIP treatment suppresses tumor growth and induces a Th1 cytokine response (a) General outline of the in vivo experiment protocol. (b) Comparison of the anti-tumor effects of MIP administered at different time points. Cohorts of ten mice were inoculated s.c. with $\sim 10^{7} \mathrm{Sp} 2 / 0$ cells. Mice were injected i.d. with a single dose of MIP $\left(\sim 5 \times 10^{8}\right)$ either one day (-1D) before or $3(+3 \mathrm{D})$ or $6(+6 \mathrm{D})$ days after tumor inoculation. Mice injected i.d. with PBS on day 3 were included as controls. The growth of tumors (mean $\pm \mathrm{SD} \mathrm{mm}^{3}$ ) at indicated days post implantation. (c) Representative photographs of solid tumors from different treatment groups dissected on day 14 (from 18).

\section{Summary}

The article recapitulates the journey taken for development of an immunoprophylactic and immunotherapeutic vaccine against leprosy. Besides leprosy, it was effective as adjunct to MDT for treatment of Category II "difficult to treat" tuberculosis patients. The relapse rate of patients treated with MDT+ MiP was much lower than those treated with MDT alone. Mycobacterium indicus pranii (MiP) is a potent invigorator of both cellular and humoral immune responses. It is a good adjuvant for generating high antibody titres in response to hCG $\beta$ LT vaccine for control of fertility. It cures ugly anogenital warts. It has both preventive and therapeutic action against development of SP2/O myelomas in mice.

\section{References}

1. Yeh RW, Sidney S, Chandra M, Sorel M, Selby JV, et al. (2010) Population trends in the incidence and outcomes of acute myocardial infarction. N Engl J Med 362: 21552165.[Crossref]

2. Fishbein MC, Meerbaum S, Rit J, Lando U, Kanmatsuse K, Mercier JC, et al. (1981) Early phase acute myocardial infarct size quantification: validation of the triphenyltetrazolium chloride tissue enzyme staining technique. Am Heart $J$ 101: 593600. [Crossref]

3. Davies MJ (1997) The composition of coronary-artery plaques. N Engl J Med 336: 1312-1314. [Crossref]

4. Effectiveness of intravenous thrombolytic treatment in acute myocardial infarction GruppoItaliano per lo Studio della Streptochinasinell' Infarto Miocardico (GISSI). Lancet 1: 397-402. [Crossref]

5. (1993) An international randomized trial comparing four thrombolytic strategies for acute myocardial infarction. The GUSTO investigators. $N$ Engl J Med 329: 673-682. [Crossref]

6. Armstrong PW, Collen D, Antman E (2003) Fibrinolysis for acute myocardial infarction: the future is here and now. Circulation 107: 2533-2537. [Crossref]

7. Grines CL, Serruys P, O'Neill WW (2003) Fibrinolytic therapy: is it a treatment of the past? Circulation 107: 2538-2542.[Crossref]

8. Logallo N, Kvistad CE, Thomassen L (2015) Therapeutic Potential of Tenecteplase in the Management of Acute Ischemic Stroke. CNS Drugs 29: 811-818. [Crossref]

9. Serebruany VL, Malinin AI, Callahan KP, Binbrek A, Van De Werf F, et al. (2003) Effect of tenecteplase versus alteplase on platelets during the first 3 hours of treatment for acute myocardial infarction: the Assessment of the Safety and Efficacy of a New 
Thrombolytic Agent (ASSENT-2) platelet substudy. Am Heart $J$ 145: 636-642. [Crossref]

10. Assessment of the Safety and Efficacy of a New Thrombolytic Regimen (ASSENT)-3 Investigators (2001) Efficacy and safety of tenecteplase in combination with enoxaparin, abciximab, or unfractionated heparin: the ASSENT-3 randomised trial in acute myocardial infarction. Lancet 358: 605-613. [Crossref]

11. Armstrong PW, Committee WS (2006) A comparison of pharmacologic therapy with/ without timely coronary intervention vs. primary percutaneous intervention early after ST-elevation myocardial infarction: the WEST (Which Early ST-elevation myocardial infarction Therapy) study. Eur Heart J 27: 1530-1538. [Crossref]

12. Cascio WE (2001) Myocardial ischemia: what factors determine arrhythmogenesis? $J$ Cardiovasc Electrophysiol 12: 726-729. [Crossref]

13. Antman EM, Louwerenburg HW, Baars HF, Wesdorp JC, Hamer B, et al. (2002) Enoxaparin as adjunctive antithrombin therapy for ST-elevation myocardial infarction: results of the ENTIRE-Thrombolysis in Myocardial Infarction (TIMI) 23 Trial. Circulation 105: 1642-1649.[Crossref]

14. Giugliano RP, Roe MT, Harrington RA, Gibson CM, Zeymer U, et al. (2003) Combination reperfusion therapy with eptifibatide and reduced-dose tenecteplase for ST-elevation myocardial infarction: results of the integrilin and tenecteplase in acute myocardial infarction (INTEGRITI) Phase II Angiographic Trial. J Am Coll Cardiol 41:1251-1260. [Crossref]

15. Armstrong PW, Collen D (2001) Fibrinolysis for acute myocardial infarction: current status and new horizons for pharmacological reperfusion, part 2. Circulation 103 : 2987-2992. [Crossref]

16. Armstrong PW (2003) Primary angioplasty or thrombolysis for acute myocardial infarction? Lancet 361: 966; author reply 967-968.

17. DeMaria AN (2008) Lies, damned lies, and statistics. J Am Coll Cardiol 52: 14301431. [Crossref]
18. Kloner RA, Braunwald E (1980) Observations on experimental myocardial ischaemia. Cardiovasc Res 14: 371-395. [Crossref]

19. Svenson KL, Bogue MA, Peters LL (2003) Invited review: Identifying new mouse models of cardiovascular disease: a review of high-throughput screens of mutagenized and inbred strains. J Appl Physiol 94: 1650-1659.[Crossref]

20. Bodary PF, Eitzman DT (2009) Animal models of thrombosis. Curr Opin Hematol 16 342-346. [Crossref]

21. Modi NB, Eppler S, Breed J, Cannon CP, Braunwald E, et al. (1998) Pharmacokinetics of a slower clearing tissue plasminogen activator variant, TNK-tPA, in patients with acute myocardial infarction. Thromb Haemost 79: 134-139.[Crossref]

22. Tsikouris JP, Tsikouris AP (2001) A review of available fibrin-specific thrombolytic agents used in acute myocardial infarction. Pharmacotherapy 21: 207-217. [Crossref]

23. Collen D, Stassen JM, Yasuda T, Refino C, Paoni N, et al. (1994) Comparative thrombolytic properties of tissue-type plasminogen activator and of a plasminogen activator inhibitor-1-resistant glycosylation variant, in a combined arterial and venous thrombosis model in the dog. Thromb Haemost 72: 98-104. [Crossref]

24. Cannon CP, Gibson CM, McCabe CH, Adgey AA, Schweiger MJ, et al. (1998) TNKtissue plasminogen activator compared with front-loaded alteplase in acute myocardial infarction: results of the TIMI 10B trial. Thrombolysis in Myocardial Infarction (TIMI) 10B Investigators. Circulation 98: 2805-2814. [Crossref]

25. Marshall RS (2015) Progress in Intravenous Thrombolytic Therapy for Acute Stroke. JAMA Neurol 72: 928-934. [Crossref]

26. Bonnefoy E, Lapostolle F, Leizorovicz A, Steg G, McFadden EP, et al. (2002) Primary angioplasty versus prehospital fibrinolysis in acute myocardial infarction: a randomised study. Lancet 360: 825-829. [Crossref]

Copyright: $(\mathbb{O} 2015$ El-Ansary D. This is an open-access article distributed under the terms of the Creative Commons Attribution License, which permits unrestricted use, distribution, and reproduction in any medium, provided the original author and source are credited. 